two or three $\mathrm{cm}$. on each side of the sternum. Auscultation is negative, except for markedly accentuated second sound at the aortic interspace. No cardiac murmurs and no bruit are heard. The lungs were found to be apparently normal. Tracheal tugging is believed to be present, though it is not marked. The veins of the infraclavicular regions are very slightly enlarged. There is marked difference between the pulsation in the carotid artery, that of the right side being strong and full, while that of the left is weak and small. The difference is perceptible on inspection, as well as on palpation. There is no apparent difference in the radial pulse of the two sides. The pupils are equal.

Diagnosis.-A diagnosis was made of aneurism of the arch of the aorta, pressing on the left recurrent laryngeal nerve.

Skiagraphic Examination.-On the following day an $x$-ray photograph of the chest was made by Dr. A. Soiland. His report is as follows: "The examination with the fluoroscope of the chest of your patient, P. H., shows a shadow about the size of an orange, above the heart and extending on each side of the sternum to an extent of $1 \frac{1 / 2}{2}$ inches. Pulsation of the shadow is apparent. I am inclined to think that it is an aneurism of the arch of the aorta."

Subsequent History.-The subsequent history has been uneventful, except for some change in the larynx. The hoarseness has increased until he can now speak only in a whisper. The left vocal cord remains in the same position of rigidity, while the excursion of the right cord, during phonation, has

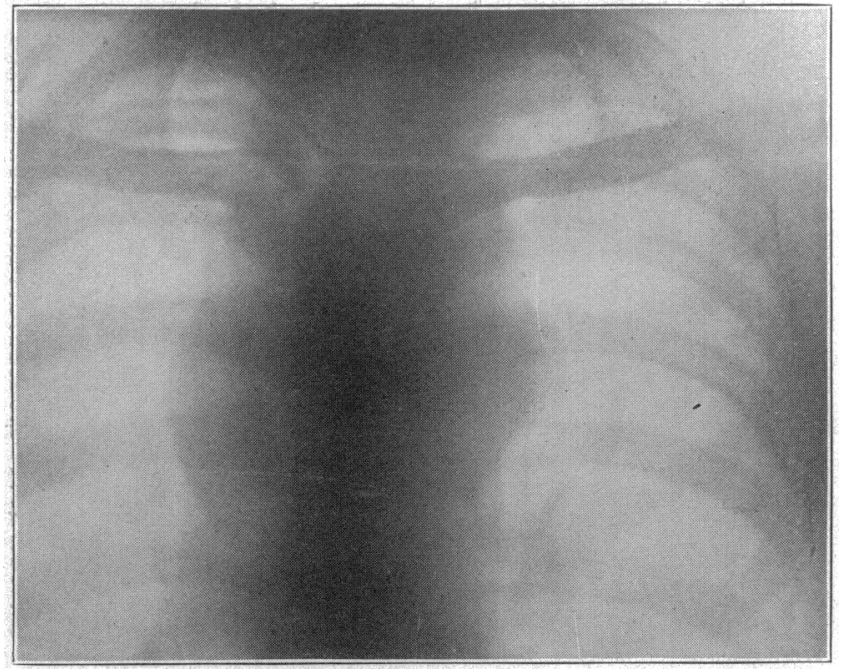

decreased so that it does not meet its fellow. The vocal processes of the two cords almost but do not quite meet during phonation, leaving a space in front and behind, the left edge of which (the free margin of the paralyzed cord) is markedly bowed. On inspiration the right arytenoid and corresponding right cord move outward, while on phonation the right aryinterpreted as due to paralysis of the arytenoideus muscle, tenoid is drawn to the opposite one sluggishly. This has been which has developed since the first examination.

Marked vicarious action of the false cords is observed. They meet during phonation to the extent of the anterior twothirds, completely preventing the view of the true vocal cords to that extent. This is believed to be due to excessive action of the thryo-arytenoideus muscles. The veins over the upper part of the chest have become somewhat more prominent, as has also the pulsation in the second aortic interspace. The griping pain referred to the upper sternal region has remained severe and is controlled only by morphin.

The medical profession must begin to get busy in the treatment of their cases. What the people demand is relief or cure of their ills, the quicker the better, and if one does not do something better for them, they are going of into other lines. Diagnosis is essential, and very essential, but after all the ultimate aim of all medical research is the prevention or cure of disease, which means therapeutics.-George F. Butler.
QUININ IN PNEUMONIA.

FRANCIS H. POOLE, M.D.

Agency Physician, Linited States Indian Service. ROSS FORK, IDALO.

In thirteen consecutive cases of pneumonia developing in the course of a recent epidemic of that disease among the Indian school children on this reservation, the patients were treated by large doses of quinin, according to the method advocated by Galbraith, ${ }^{1}$ without mortality. Some observations on the effects of the treatment, particularly its tendency to induce nasal and uterine hemorrhage, are given below:

Five cases developed in boys ranging in age from 7 to 13 years, and eight developed in girls between the ages of 9 and 17 . The initial symptoms common to all cases were intense frontal headache, epigastric distress and vomiting, while in eight cases epistaxis also occurred during the onset.

Of the five boys, three suffered epistaxis as an initial symptom and all had repeated nasal hemorrhages during the administration of the quinin and iron treatment.

Of the eight girls, five suffered epistaxis during the onset; two of these five, aged respectively 11 and 13 years, in whom the menstrual function was not yet established, began menstruating shortly after treatment was begun, but had no further nasal hemorrhages while under treatment. Of the three others with an initial epistaxis, the hemorrhage recurred repeatedly during the treatment. The remaining three girls in whom epistaxis was not noted as an initial symptom, aged respectively 13,14 and 17 years, began menstruating during treat ment, although in none of these cases were the menses due and all were of known regularity with respect to periodicity.

Was this great tendency to hemorrhage from initial symptoms to crisis a part of the disease, peculiar to this particular epidemic, or were the nasal hemorrhages incident to the onset due to infection and the subsequent ones to the treatment?

Quinin in large doses proved a genuine stimulant to the heart and circulation and appeared, in a large measure, to allay the anxiety and apprehension and to secure sleep.

The lung involvement was as follows:

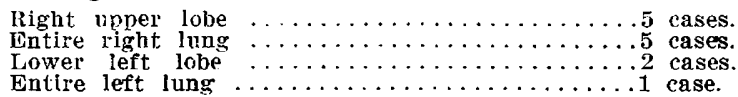

Entire left lung

The minimum single dose of quinin given was fifteen grains and the maximum single dose thirty-six grains.

As present-day investigators are united in the belief that the exciting etiologic factor of pneumonia is nearly always present in the circulating blood, if indeed the disease is not regarded as essentially a primary pneumococcic septicemia with a secondary process in the lungs, and acknowledging the antiseptic properties of quinin and iron, is not the line of treat ment advocated by Dr. Galbraith a rational one?

\section{IMMEDIATE CLOSURE OF TRACHEOTOMY WOUNDS.}

THOMAS C. HOOVER, M.D.

l'rofessor of Surgery, Starling Medical College. COLUMBUS, OHIO.

The cases reported by Miles F. Porter, M.D., Fort Wayne, Ind., prompt me to report the following:

Baby girl, aged $2 \frac{1}{2}$ years, referred to me by Dr. Quin, West Jefferson, Ohio, Feb. 18, 1898.

The evening before the child had been playing with some corn and a grain lodged in the trachea. When she arrived at my office, having been conveyed in an open buggy eighteen miles, she was breathing easily, but she had a paroxysm of dyspnea while I was examining her.

Low tracheotomy was immediately performed and the grain of corn presenting at the tracheal opening was removed without difficulty. I closed the wound throughout with fine catgut, beginning with the trachea. The recovery was prompt and without unfavorable incident. No drain was used.

If surgical cleanliness is used there certainly can not be any good reason for using the open method in non-infectious rases of tracheotomy.

1. The JovRxat, Jan. 28, 1005, p. 291. 